\title{
К ВОПРОСУ О ВЫБОРЕ СЛОВАРЯ (НА МАТЕРИАЛЕ СЛОВАРЕЙ ИСТОРИЧЕСКИХ ТЕРМИНОВ)
}

\author{
М. Н. Панютина
}

Ивановский государственный университет

\section{TO THE QUESTION OF CHOOSING A DICTIONARY (BASED ON DICTIONARIES OF HISTORICAL TERMS)}

\author{
M. N. Paniutina \\ Ivanovo State University
}

\begin{abstract}
Аннотация: в статье поднимается вопрос актуальности выбора словаря для специальных целей в рамках современного функиионального подхода, т. е. с учетом запросов пользователей. В этой связи рассматриваются принципы построения двух авторитетных отечественных двуязычного и многоязычного словарей исторических терминов междисииллинарного характера - Англо-русского исторического словаря: 30000 имен, названий, терминов Г. А. Николаева и Словаря исторических терминов, понятий и реалий: Русский. Английский. Франиузский. Немеикий Е. Л. Хохловой. Описывается тип каждого словаря, подробно анализируются его мега-, макро- и микроструктура; делаются выводы об антропочентричности, направленности на адресата, культурологической, дидактической значимости и привлекательности для пользователя. Вносятся элементы авторской критики отдельных приничипов оформления указанных справочных изданий. Исследование аккумулирует современные положения лексикографии и основывается на актуальном лингвистическом материале англоязычных словарей. Лексикографический анализ проведен по общепринятым параметрам: язык, источник, адресат, формат, объем, критерии отбора лексики в словарь и способы лексикографической обработки слова. Для написания статьи использован объемный практический материал, включающий не только словари Г. А. Николаевой и Е. Л. Хохловой, но и имеющиеся в свободном доступе англо-русские словари исторических терминов. Исследование ориентировано в первую очередь на студентов исторического профиля подготовки, а также на переводчиков, преподавателей и людей, изучающих иностранные языки с различными целями. В статье подчеркивается практическая значимость проделанной работь, поскольку результаты планируется применять на практических занятиях в вузах и других учебных заведениях.
\end{abstract}

Ключевые слова: лексикографический анализ, мега-, макро-, микроструктура словаря, помета.

Abstract: the article deals with the importance of the choice of a dictionary for specific purposes taking into account the functional approach and users 'perspective. Thereby the architecture of the following prominent dictionaries of historical terms is viewed: English-Russian Historical Dictionary: 30000 Names, Titles and Terms by G. A. Nikolaev; Dictionary of Historical Terms, Notions and Realia: Russian, English, French, German by E. L. Khokhlova. The dictionary type of every dictionary under analysis is described as well as its mega-, macroand microstructure. It is concluded that the dictionary is anthropocentric, user-oriented and user-friendly, culturally and didactically significant. Several principles of the architecture of the dictionaries under analysis are criticized. The research and the article are based on the contemporary linguistic material and accumulate all the crucial lexicographic theories and concepts. Lexicographic analysis was conducted according to the following generally accepted criteria: language, source, addressee, type, volume, criteria of vocabulary selection, and means of lexicographic processing of a word in a dictionary. Considerable practical material was used for the article including the given dictionaries under analysis alongside other accessible English-Russian dictionaries of historical terms. The article is for students of History Department, translators, educators and people learning

(C) Панютина М. Н., 2021

Контент доступен под лицензией Creative Commons Attribution 4.0 License.

The content is available under Creative Commons Attribution 4.0 License. 
foreign languages for different purposes. The practical slant of the article and the research is evident as the obtained results are planned to be used during the classes at the university and other educational institutions.

Key words: lexicographic analysis, megastructure, macrostructure, microstructure, dictionary label.

\section{Введение}

Проблема выбора словаря для конкретных целей является основной в теории и практике лексикографии, как и вопрос о классификации словарей [1]. Поскольку в современной лексикографии в связи с изменением ее парадигмы в условиях цифровизации [2] на передний план выходят нужды и требования пользователя, вопрос о выборе словаря выдвигает ряд требований: доступность, информативность, полнота словника и лексикографической обработки и т. д. В этой связи необходим лексикографический анализ различных типов словарей, который позволит адресату отобрать конкретный тип справочника для чтения, перевода, устного выступления и других целей.

Лексикографический анализ является основным инструментом комментирования и критики текстов словарей. Он способствует сравнению их между собой, выявляет их достоинства и недостатки, приводит к обобщениям и предложениям по усовершенствованию словарей [3].

Лексикографический анализ проводится по следующим параметрам: язык, источник, адресат, формат, объем, критерии отбора лексики в словарь и способы лексикографической обработки слова. Эти параметры выработаны отечественной школой лексикографии и получили апробацию в многочисленных исследованиях, а также при создании авторских моделей словарей (3. Р. Алхастовой, М. В. Бурлаковой, О. В. Германовой, И. В. Петросян, К. В. Пиоттуха и др.). Они относятся к анализу одноязычных и двуязычных словарей, как для общих, так и для специальных целей $[4 ; 5]$.

В двуязычной лексикографии накоплен достаточно большой опыт создания словарей английских исторических терминов. Среди них Иллюстрированный англо-русский, русско-английский историко-археологический словарь О. Е. Алексеевой и Н. Ф. Саввониди; Частотный англо-русский словарь - подъязык истории В. Н. Безбородовой и О. А. Остриковой; Краткий англо-русский словарь исторических терминов Е. Ф. Абрамчик, Е. Ю. Бригадиной, М. И. Нечаевой и др.; Англо-русский исторический словарь: 30000 имен, названий, терминов Г. А. Николаева; Словарь исторических терминов, понятий и реалий: Русский. Английский. Франиузский. Немеикий Е. Л. Хохловой и $п р$.

Однако, как показал опыт, чаще всего пользователи обращаются к двум наиболее авторитетным словарям, которые будут проанализированы в настоящей статье. В этой связи представляется целесо- образным рассмотреть принципы построения двуязычного и многоязычного словарей, регистрирующих и обрабатывающих исторические термины. Это словари Г. А. Николаева и Е. Л. Хохловой.

\section{Результаты исследования}

Николаев Г. А. Англо-русский исторический словарь : 30000 имен, названий, терминов. М. : Прогресс ; Лексикон, 1995. 464 c.

Словарь является двуязычным (англо-русским), однонаправленным с переводом английских слов на русский язык. Он имеет лексикографическую форму глоссария и печатный формат большого объема (30 000 слов).

Это первый опыт издания англо-русского аннотированного словаря исторических терминов, имен и названий. Справочник предназначен для перевода текстов литературы по общественным наукам. Наряду с историческими терминами и названиями исторических событий в словник включены термины по археологии, этнографии, архитектуре, мифологии, истории религии, названия древних и современных народов, государств и организаций, исторические названия современных городов и т. Д., что свидетельствует о междисциплинарном характере словаря. Источниками стали словари, энциклопедии, издания по истории и мифологии различных стран и народов на русском и английском языках.

Данное справочное пособие ориентировано на широкий круг пользователей: переводчиков, специалистов в области общественных наук, студентов и пр. Оно относится к пассивному типу, обеспечивая адресату процесс понимания значения слов на иностранном языке.

Словарь имеет уникальную черту - снабжает большинство статей небольшими аннотациями, что выгодно отличает его от других терминологических справочников исторических терминов. Аннотации содержат краткую характеристику явления или события, в том числе дату и название государства; в персоналиях указаны годы жизни или правления (для древних правителей) и содержится краткое определение: государственный деятель, политический, коммунистический, военный, религиозный и т. п. В случае если имена исторических деятелей полностью совпадают, они перечисляются в хронологическом порядке и обозначаются арабскими цифрами. Например:

William I 1) Вильгельм I Длинная Шпага, нормандский герцог (ум. 942); 2) Вильгельм I Завоеватель, англ. Король (1028-87)... 
T'ai-tsung Тайцзун: 1) кит. император (600-649); кит. император (939-997).

Мегаструктура словаря состоит из Предисловия, Списка сокращений, Английского алфавита, Словника и Списка Литературы. В Предисловии изложены правила пользования словарем, в котором принята смешанная алфавитная и алфавитно-гнездовая система.

Макроструктура включает входные единицы (A-Z).

В словник включены имена существительные: magister магистр, должность в Древнем Риме, Византии и средневековой Европе; equitum магистр всадников, помощник диктатора; militum главнокомандующий; тогит цензор; officiorum магистр, ведавший внешней политикой и контролем над провинциями; populy диктатор.

Имена собственные, отражающие культурный код нации и картину англоязычного мира в целом, а также знакомящие пользователя с историей, археологией, мифологией, архитектурой, религией и т. д.: Hohenzollern dynasty; Sucellus; Themis.

Имена исторических деятелей: Edbert; Rivet, Paul; Zwingly, Huldrych.

Среди имен собственных особо выделяются топонимы, являющиеся культурными маркерами и описывающие картину мира человека разных эпох и стран: Bernicia; Maginot Line; Saudi Arabia.

Макроструктура регистрирует глаголы и другие знаменательные слова. Например, accurse; back; retire. Однако регистрация глаголов дается лишь в исходной форме, в то время как словоизменительные формы не фиксируются.

Имена прилагательные: retired; Pre-Conquest; nomadic.

Существенно повышает информативность словаря введение в словник аббревиатур, появление которых отражает мировые тенденции к интеграции в самых различных областях, будь то политика, экономика, культура и т. д. Включение в словник аббревиатур отличает данный словарь от других существующих справочников и является несомненным достоинством этого издания, так как попытки самостоятельно расшифровать некоторые из аббревиатур нередко вызывают вполне объяснимые затруднения у пользователей): OPEC; NATO; SPD.

В макроструктуре также фиксируются антропологические, археологические, архитектурные, библейские, военные, геологические, мифологические, морские, политические, религиозные, философские, церковные, экономические, этнографические и юридические термины: abaciscus - apxuт. плитка мозаики; portal dolmen - археол. портальный дольмен, разновидность мегалит. гробницы.

Входные единицы представлены в канонической форме. Словообразовательные формы помещены в отдельных словарных статьях, что, на наш взгляд, является недостатком данного справочника. Пример: abbey; abbot; balista = ballista; balistraria .

Поскольку определенную сложность часто вызывает передача имен и фамилий (например, иногда переводчик ошибочно именует св. Иоанна Богослова Джоном Теологом, а дворец Ирода Великого, упоминаемый в известном романе Булгакова, дворцом Геродота), в словарь включена подборка имен виднейших деятелей мировой истории, которая, разумеется, не является всеобъемлющей, но в ряде случаев отсутствия той или иной фамилии позволяет передать ее по аналогии.

Микроструктура имеет универсальную структуру и содержит заглавную единицу, ее перевод на русский язык, а также ряд помет, например, несколько вариантов толкования данного термина и хронологические пометы: Hasidism 1) евр. религ. движение в Германии (12-13 вв.); 2) религиозно-мистическое движение в иудаизме (18-20 вв).

В алфавите учитывается вначале первое слово (Tripolitan War, затем Tripolitania), а также слово, отделенное запятой (Trade, Board of, затем trade agreement); преимуществом пользуются слова, начинающиеся с прописной буквы: Tin (этрусский бог), затем tin (олово); название с дефисами или апострофами считается одним словом (life insurance, затем life-annuity u life-guard). Археологические и политические термины, состоящие из определяемых слов и определений, расположены по алфавитно-гнездовой системе, их следует искать по определенным словам, например, термин backed blade находится в гнезде blade. Ведущие термины в гнезде заменяются тильдой $(\sim)$. Пояснения к русским эквивалентам набраны курсивом и заключены в скобки, например, расторжение (договора). В переводах принята следующая система разделительных знаков: близкие значения отделены запятой, более далекие - точкой с запятой, различные значения - цифрами.

Составитель стремился дать не просто буквальный перевод термина или названия, а принятый в отечественной исторической литературе термин, проверенный по отечественным источникам, поэтому в ряде случаев дается отсылка на другое название. Например: Bloodless Revolution, cм. Glorious Revolution. Буквальный перевод «Бескровная революция» приводить не имеет смысла, так как в отечественной литературе так ее не называют, тогда как название Glorious Revolution содержит краткую аннотацию - «Славная революция» 1688-89 в Англии.

Тем же способом, но с переводом приводятся редко употребляемые у нас термины и названия, например: Black Sheep «чернобаранные» (cм. Kara Koyunlu ), где дается подробная аннотация - Кара-Коюнлу, гос-во... 
После перевода термина в угловых скобках могут быть указаны существующие варианты написания, например: aшар 〈ушр〉, натуральный десятинный налог...; Хлотарь 〈Клотар; Хлотахар〉...; другие названия, например: шампар 〈терраж〉; встречающиеся в литературе транслитерации термина, например: черноногие 〈блэкфут〉 и т. п.

В круглых скобках помещены малоизвестные части имен, например: Balaguer (y Ricardo), Joaquin Vidella, а также краткие аннотации, например: (история наполеоновских войн, 1809).

В случае когда двум или более английским терминам соответствует один русский, они связываются обычной в словарях отсылкой в виде знака равенства $(=)$, например: arblast $=$ arbalest.

Существующий в английской литературе синоним слова Josephites (иосифляне) Possessors, возникший, очевидно, в противоположность Non-Possessors (нестяжатели), также решено не переводить, поэтому дана отсылка на название, где будет помещена аннотация: Possessors $=$ Josephites.

Поскольку имена деятелей отечественной истории в английском написании легко узнаваемы, в англо-русский вариант включены только иностранные фамилии (Dzerzhinsky, Kollontay, Kollataj), в том числе натурализованных иностранцев (Bennigsen, Biron). Имена царей (Fyodor, Vasily) помещены в связи с существованием таких форм, как Theodor $u$ Basil и опасностью перепутать их, например, с именами византийских императоров.

Объем сведений, представленных в словаре, позволяет читателю, владеющему английским языком и основами транслитерации, пользоваться им как кратким историческим справочником.

Словарные статьи на странице размещены в двух столбцах. Иллюстративное оформление отсутствует.

Заглавное слово выделено жирным шрифтом, употребительная помета - курсивом; дефиниция обычным шрифтом, без выделения. В случае когда термин имеет несколько толкований, перевод дается в одной словарной статье под цифрами 1); 2); и т. д. Например: property 1) собственность, имущество; 2) свойство, качество.

Таким образом, лексикографический анализ Англо-русского исторического словаря Г. А. Николаева свидетельствует об информативности данного справочного пособия. Его можно рекомендовать пользователю, поскольку он предоставляет внушительный объем сведений из самых разных областей исторической, археологической, этнографической и других смежных с историей наук. Это самый масштабный по охвату материала англо-русский словарь исторических терминов.
Хохлова Е. Л. Словарь исторических терминов, понятий и реалий : Русский. Английский. Франиузский. Немеикий / под ред. Ю. Н. Марчука.

2-е изд., стер. М. : Флинта, 2012. 160 c.

Словарь представлен в новом электронном формате в оцифрованном виде печатного издания - наиболее распространенной форме электронных справочников [6].

Справочник охватывает различные аспекты исторической науки. В нем также широко представлены термины истории религии и церкви, международных отношений, экономики, архитектуры, археологии, военного дела, этнографии и других областей, тесно связанных с историей.

Следует отметить, что этот многоязычный словарь объединяет терминологию исторической науки на основных европейских языках - английском, французском, немецком и русском. Расширяется объем языков, что значительно повышает его информативную ценность. Данный словарь обобщает имеющийся опыт исторической терминографии; большое преимущество словаря для русскоязычных пользователей заключается в том, что входным языком в словаре является русский.

В словарь включена лексика церковно-христианской тематики, которая многие годы оставалась вне внимания лексикографов. В последние годы этот пробел во многом был восполнен усилиями историков, лингвистов, служителей церкви: были выпущены словари данной тематики. По мнению авторов, лексика, отражающая состояние сознания и идеологии населения Европы, должна присутствовать в словаре, отражающем исторические понятия и реалии.

Словарь предназначен для студентов и преподавателей языковых вузов и гуманитарных специальностей, иностранных студентов, изучающих русский язык, переводчиков, историков, гидов, а также всех, кто интересуется мировой историей и культурой.

В словарь включены исторические термины и понятия на русском, английском, французском и немецком языках, всего около 1800 словарных статей.

Мегаструктура включает Предисловие, Правила пользования словарем, Словник (А-Я) и список используемых сокращений.

Словарные статьи на странице размещены в двух столбиках. Представленные дефиниции являются вербальными. Отсутствие иллюстраций и цветового оформления является недостатком данного учебного пособия, так как снижает эффективность восприятия материала.

Макроструктура включает словосочетания типа «прилагательное + существительное», обозначающих видовое и родовое понятия, сначала дается родовое 
понятие, особенно если подряд следует несколько словарных статей по видовым понятиям одного родового понятия: соглашение, двустороннее; соглашение, межсправительственное; соглачение, многостороннее.

Микроструктура построена следующим образом - заглавная лексема (термин, терминологическое словосочетание) на русском языке, она выделена жирным шрифтом, затем - толкование; далее приводятся переводы на английском, французском и немецком языках. За словом (словосочетанием) в каждом языке следует курсивом необходимая грамматическая информация: род существительного (в словосочетании - главного слова), окончание множественного числа, если множественное число образуется не по правилам, например: Акрополь м // возвышенная и укрепленная часть древнегреческого города; acropolis, pl-leis; acropole f; Akropolis $f, p l$-polen.

В словаре используются грамматические пометы: род, число, множественное число рода существительного в русском языке. После грамматической информации часто дается курсивом стилистическая помета, которая относит данное понятие к той или иной более узкой сфере употребления, таким образом, уточняя его терминологическое значение. Пример: авункулат м этн. // установленная обычаем особенно тесная связь между дядей с материнской стороны и племянниками; avunculate; avunculat m; Avunculat $n$.

Принятые в словаре пометы, определяющие отношение к предметной области: aнтроп. - антропология; археол. - археология; архит. - архитектура; библ. - библейское; воен. - военное дело; геол. - геология; дип. - дипломатия и др.

После знака // в большинстве словарных статей дается толкование данного термина или понятия, что призвано существенно повысить эффективность работы с данным словарем, который, по сути, является переводным. Наличие толкования дает возможность пользователю не привлекать дополнительные энциклопедические источники для выяснения содержания того или иного понятия или исторической реалии.

Варианты переводных эквивалентов разделяются запятой; варианты терминов и понятий в русском языке даются в соответствующем алфавитном порядке со ссылкой на основную словарную статью: $A$ - $^{-}$ тичность ж = античный мир.

Факультативная часть термина помещена в круглые скобки.

Данный словарь является в первую очередь лексикографическим продуктом, а не энциклопедическим изданием, т. е. основное внимание авторов сосредоточено на переводных эквивалентах термина, а не на его толковании, представленном в большей степени как лингвистическая дефиниция, а не как исчерпывающее энциклопедическое объяснение понятия.
Объем словаря средний.

Таким образом, словарь Е. Л. Хохловой представляет собой электронный вариант печатного справочника, наиболее привлекательный для современного пользователя, и включает термины и реалии на четырех языках, т. е. является многоязычным глоссарием, дифференциальным по словнику и лексикографической обработке. Словарь имеет междисциплинарный характер и охватывает различные аспекты истории религии и церкви, международных отношений, экономики, архитектуры, археологии, военного дела, этнографии, а также других областей, тесно связанных с историей.

Поскольку целевая аудитория словаря достаточно многообразна - студенты, преподаватели языковых вузов и гуманитарных специальностей, иностранные студенты, изучающие русский язык, переводчики, историки, гиды - он имеет как учебную, так и культурологическую направленность. Издание представляет несомненную ценность для всех, кто интересуется мировой историей и культурой.

\section{Заключение}

В заключение отметим, что результаты лексикографического анализа двух авторитетных словарей исторических терминов позволяют рекомендовать их целевой группе пользователей, т. е. студентам, по следующим причинам:

- оба издания имеют междисциплинарный характер, так как описывают не только исторические термины, но и термины из других гуманитарных наук;

- включают довольно большой объем входных единиц - несколько десятков тысяч слов;

- имеют информативную мегаструктуру, построенную в удобном алфавитном порядке;

- словарные статьи включают широкий спектр помет - грамматические, стилистические, употребительные, хронологические и т. д.

Перечисленные выше параметры свидетельствуют о богатой информативности словарей, а электронный формат позволяет расширить круг целевой аудитории и обеспечивает популярность справочных изданий.

\section{ЛИТЕРАТУРА}

1. Карпова О. М. Еще раз о типологии словарей (на материале английских словарей нового поколения) // Вестник Иван. гос. ун-та. Сер.: Гуманитарные науки. 2019. № 3 (12). С. 12-16.

2. Карпова О. М., Денисов К. М. Современная мировая лексикография и эволюция ее научной парадигмы // Вестник Иван. гос. ун-та. Сер.: Гуманитарные науки. 2018. Вып. 1. С. 39-43.

3. Чайникова Г. Р. Разработка учебного электронного словаря тезаурусного типа как средства формирования 
внутреннего иноязычного лексикона // Вестник ПНИПУ. Проблемы языкознания и педагогики. 2014. С. 70-84.

4. Алхастова 3. Р., Карпова О. М. Лексикография культурного наследия (на материале словарей языка английских писателей, цитат и пословиц) / отв. ред. О. М. Карпова. Иваново : Изд-во ИвГУ, 2020. 172 с.

5. Пиоттух $K . B$. Из истории развития английской лексикографии (лексикографический анализ словаря Chambers's Twentieth Century Dictionary of the English Language printed in 1901, reprinted in 1911. Edinburgh : W. \& R. Chambers) // Вестник Воронеж. гос. ун-та. Сер.: Лингвистика и межкультурная коммуникация. 2017. № 4 C. 181-186.

6. Карпова О. М. Словарь как инструмент пользователя информационного пространства // Новая экономика и региональная наука. 2018. № 2. С. 46-52.

\section{ИСТОЧНИКИ}

1. Алексеева О. Е., Саввониди Н. Ф. Иллюстрированный англо-русский, русско-английский историко-археологический словарь. СПб. : Издательство ПК «Завод Вибратор», 1993. 111 с.

2. Безбородова В. Н., Острикова О. А. Частотный англо-русский словарь - подъязык истории. Ленинград : Изд-во Ленинград. ун-та, 1984. 136 с.

3. Краткий англо-русский словарь исторических терминов / авт.-сост.: Е. Ф. Абрамчик и др. ; под общ. ред. Л. В. Хведчени. Минск : БГУ, 2004. 79 с. (Краткий терминологический словарь.)

4. Николаев Г. А. Англо-русский исторический словарь : 30000 имен, названий, терминов. М. : Прогресс ; Лексикон, 1995. 464 с.

5. Хохлова Е. Л. Словарь исторических терминов, понятий и реалий : Русский. Английский. Французский. Немецкий / под ред. Ю. Н. Марчука. 2-е изд., стер. М. : Флинта, 2012. 160 с.

\section{REFERENCES}

1. Karpova O. M. Eshhe raz o tipologii slovarej (na materiale anglijskikh slovarej novogo pokoleniya) [Typology of dictionaries (based on English dictionaries of the new generation)]. In: Vestnik Ivanovskogo gosudarstvennogo universiteta. Seriya: "Gumanitarnye nauki». 2019. Issue 3 (12). Pp. 12-16.

2. Karpova O. M., Denisov K. M. Sovremennaya mirovaya leksikografiya i ehvolyutsiya ee nauchnoj paradigmy [Contemporary global lexicagraphy and its science paradigm evolution]. In: Vestnik Ivanovskogo gosudarstvennogo universiteta. Seriya: "Gumanitarnye nauki». 2018. Issue 1. Pp. 39-43.

Ивановский государственный университет

Панютина М. Н., аспирант кафедры зарубежной филологии

E-mail: marinapanyutina@mail.ru
3. Chajnikova G. R. Razrabotka uchebnogo ehlektronnogo slovarya tezaurusnogo tipa kak sredstva formirovaniya vnutrennego inoyazychnogo leksikona [Designing an e-dictionary thesaurus for educational purposes as a tool for building foreign lexicon]. In: Vestnik PNIPU. Problemy yazykoznaniya i pedagogiki. 2014. Pp. 70-84.

4. Alkhastova Z. R., Karpova O. M. Leksikografiya kul'turnogo naslediya (na materiale slovarej yazyka anglijskikh pisatelej, tsitat i poslovits) [Lexicography of cultural heritage (based on dictionaries of English writer`s language, quotes and idioms)]. Ed. by O. M. Karpova. Ivanovo: Izd-vo IvGU, 2020. $172 \mathrm{p}$.

5. Piottukh K. V. Iz istorii razvitiya anglijskoj leksikografii (leksikograficheskij analiz slovarya Chambers's Twentieth Century Dictionary of the English Language printed in 1901, reprinted in 1911. Edinburgh : W. \& R. Chambers) [From the history of English lexicography (lexicographic analysis of Chambers's Twentieth Century Dictionary of the English Language printed in 1901, reprinted in 1911. Edinburgh : W. \& R. Chambers) ]. In: Vestnik VGU. Seriya: Lingvistika i mezhkul'turnaya kommunikatsiya. 2017. No. 4. Pp. 181-186.

6. Karpova O. M. Slovar' kak instrument pol'zovatelya informatsionnogo prostranstva [Dictionary as a user's tool]. In: Novaya ehkonomika i regional'naya nauka. 2018. Issue 2. Pp. 46-52.

\section{SOURCES}

1. Alekseeva O. E., Savvonidi N. F. Illyustrirovannyj anglo-russkij, russko-anglijskij istoriko-arkheologicheskij slovar' [Illustrated English-Russian and Russian-English historical and archeological dictionary]. Sankt-Peterburg : Izdatel'stvo PK «Zavod Vibrator», 1993. 111 p.

2. Bezborodova V. N., Ostrikova O. A. Chastotnyj anglo-russkij slovar' - pod"yazyk istorii [English-Russian dictionary of frequent usage - a sub-language of history]. Leningrad: Izdatel'stvo Leningradskogo universiteta, 1984. $136 \mathrm{p}$.

3. Kratkij anglo-russkij slovar' istoricheskikh terminov [English-Russian dictionary of historical terms]. Avt.-sost.: E. F. Abramchik i dr.; ed. by L. V. Khvedcheni. Minsk : BGU, 2004. 79 p. (Kratkij terminologicheskij slovar'.)

4. Nikolaev G. A. Anglo-russkij istoricheskij slovar': 30000 imen, nazvanij, terminov [English-Russian Historical Dictionary: 30000 Names, Titles and Terms]. Moscow: Izdatel'skaya gruppa «Progress», «Leksikon», 1995. 464 p.

5. Khokhlova E. L. Slovar' istoricheskikh terminov, ponyatij i realij: Russkij. Anglijskij. Frantsuzskij. Nemetskij [EHlektronnyj resurs] [Dictionary of Historical Terms, Notions and Realia: Russian, English, French, German]. Ed. by YU. N. Marchuk. Issue 2. Moscow: Flinta, 2012. 160 p.

Ivanovo State University

Paniutina M. N., Post-graduate Student of the Foreign Philology Department

E-mail: marinapanyutina@mail.ru 
Поступила в редакиию 2 сентября 2021 г. Принята к публикации 15 октября 2021 г.

\section{Для цитирования:}

Панютина М. Н. К вопросу о выборе словаря (на материале словарей исторических терминов) // Вестник Воронежского государственного университета. Серия: Лингвистика и межкультурная коммуникация. 2021. № 4. C. 119-125. DOI: https://doi.org/10.17308/lic.2021.4/3819
Received: 2 September 2021

Accepted: 15 October 2021

\section{For citation:}

Paniutina $M$. N. To the question of choosing a dictionary (based on Dictionaries of Historical Terms). Proceedings of Voronezh State University. Series: Linguistics and Intercultural Communication. 2021. No. 4. Pp. 119-125. DOI: https://doi.org/10.17308/lic.2021.4/3819 